\title{
Change in salivary physiological stress markers by spa bathing
}

\author{
Masahiro Toda ${ }^{1}$, Kanehisa Morimoto ${ }^{1}$, Shingo Nagasawa ${ }^{2}$ and Kazuyuki Kitamura ${ }^{2}$ \\ ${ }^{1}$ Department of Social and Environmental Medicine, Osaka University Graduate School of Medicine, Osaka, and ${ }^{2}$ Yanaihara Institute \\ Inc., Fujinomiya-shi, 418-0011 Shizuoka, Japan
}

(Received 5 September 2005; and accepted 22 December 2005)

\begin{abstract}
We assessed the stress relief effect of spa bathing by measuring sensitive salivary stress markers, cortisol and chromogranin A (CgA). From 12 healthy males, saliva samples were collected immediately before and after spa bathing, and $30 \mathrm{~min}$ after that. Salivary cortisol and CgA levels were determined by ELISA. Salivary cortisol levels decreased after spa bathing. This tendency was more pronounced in individuals with higher levels of stress. The high-stress group showed lower salivary $\mathrm{CgA}$ levels after spa bathing, while the low-stress group higher salivary $\mathrm{CgA}$ levels in the same condition. These findings suggest that the spa bathing has a moderate affect on the stress relief.
\end{abstract}

Subjectively, spa bathing seems to relieve stress. Bathers usually experience a sense of well-being and relaxation during spa bathing. The stress-relieving effects of spa bathing, however, have not yet been scientifically established and are still anecdotal. Many studies on the physiological effects of sauna bathing have been conducted. Reports show that the secretion of anterior pituitary hormones, growth hormone and prolactin, increases during sauna bathing $(5,8-11)$. Effects on the sympathetic-adrenomedullary system have also been established. While noradrenaline concentrations increase after sauna bathing $(3,5,6,8,9)$, adrenaline levels change less consistently $(8,9)$. Meanwhile, results showing the effects of sauna bathing on the pituitary-adrenocortical axis (secretion of ACTH and cortisol) have also been inconsistent $(4,5,8,9,11)$.

To the knowledge of the authors, there have been few similar studies on the effects of spa bathing. Therefore, in the present study we set out to investi-

Address correspondence to: Prof. Kanehisa Morimoto Department of Social and Environmental Medicine, Osaka University Graduate School of Medicine, 2-2 Yamada-Oka, Suita, Osaka 565-0871, Japan Tel: +81-6-6879-3920, Fax: +81-6-6879-3929

E-mail: morimoto@envi.med.osaka-u.ac.jp gate the stress relief effects of spa bathing by measuring cortisol and $\mathrm{CgA}$ (chromogranin A), sensitive salivary stress markers, in samples taken before and after spa bathing. $\mathrm{CgA}$ is an acidic glycoprotein that localizes in the secretory granules of a wide variety of endocrine and neuronal tissues $(15,16,18)$. In particular, the level of salivary $\mathrm{CgA}$ provides a sensitive and reliable index for evaluating psychological stress (13). It is believed that salivary cortisol levels accurately reflect the free fraction of cortisol in plasma (7).

\section{MATERIALS AND METHODS}

We recruited 12 healthy male students at Osaka University to take part in the study. None were receiving any medication. Their characteristics are shown in Table 1.

They casually bathed in a local spa for $60 \mathrm{~min}$. The average temperature of the spa water was 42.0 ${ }^{\circ} \mathrm{C}$ and the mineral composition of the spa water is sodium and chloride. Saliva samples were collected immediately before $(16: 30)$ and after spa bathing $(17: 30)$, and 30 min later $(18: 00)$ using Salivette ${ }^{\circledR}$ (Sarstedt Co. Ltd., Nümbrecht, Germany). This method involves extracting saliva samples by centrifuging (at 3,000 rpm for $15 \mathrm{~min}$ ) the cotton wads 
Table 1 Subject characteristics $(n=12)$

\begin{tabular}{ccccc}
\hline \multicolumn{5}{c}{ Values (mean \pm SD) } \\
\hline Age $(\mathrm{yrs})$ & Height $(\mathrm{cm})$ & Body weight $(\mathrm{kg})$ & GHQ-28 & Zung-SDS \\
\hline $22.3 \pm 2.5$ & $172.7 \pm 6.0$ & $66.6 \pm 7.4$ & $5.0 \pm 2.9$ & $35.9 \pm 6.2$ \\
\hline
\end{tabular}
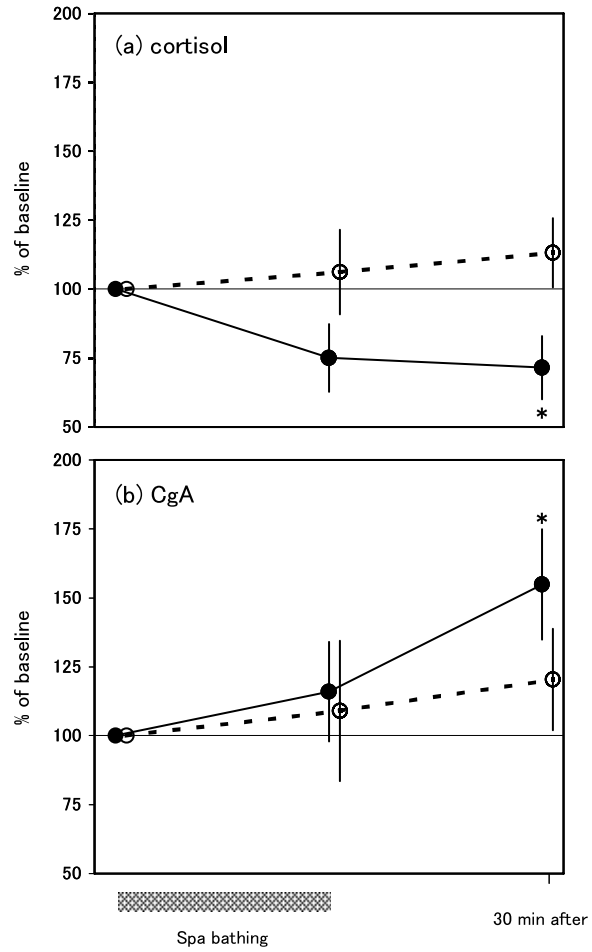

Fig. 1 Mean values ( \pm SE) normalized as percentage of baseline (before spa bathing) for (a) salivary cortisol and (b) $\mathrm{CgA}$ (chromogranin A) levels in samples taken during the spa protocol (O) and in control samples ( $\bigcirc)$. ${ }^{*}$ Significantly different from "before spa bathing", $p<0.05$ (repeated measures ANOVA and Dunett's test).

that the subjects held in their mouths (for $2 \mathrm{~min}$ ) at the time of sampling. For control, saliva samples were collected at the same times on another day. On both days, subjects were requested to refrain from eating and drinking from $2 \mathrm{~h}$ before the sampling began at $16: 30$ to the taking of the final sample at $18: 00$ (17). The samples were stored at $-80^{\circ} \mathrm{C}$ until the assay. The salivary cortisol and CgA levels were determined by ELISA, using a previously described method $(12,14)$.

Before the experiment, mental health status was evaluated using GHQ-28 (2) and Zung-SDS $(1,19)$. In addition, subjective stress immediately before and after spa bathing was measured using a ten-division visual analog scale.

Values were normalized as percentages of the
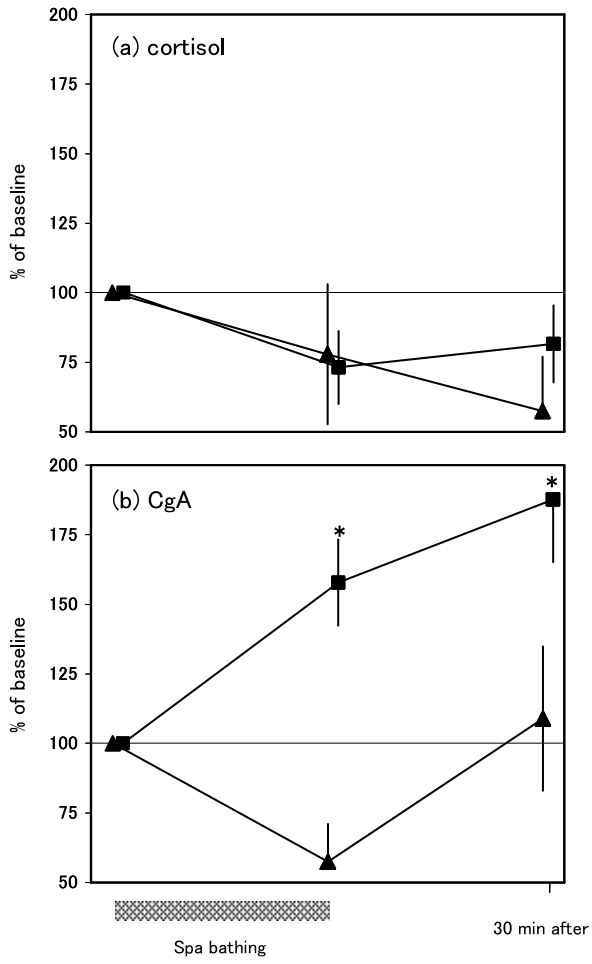

Fig. 2 Mean values ( \pm SE) normalized as percentage of baseline (before spa bathing) for (a) salivary cortisol and (b) $\mathrm{CgA}$ (chromogranin A) levels in high-stress group $(\boldsymbol{\Lambda}: n=5)$ and in low-stress group $(\boldsymbol{\square}: n=7)$ samples taken during the spa-bathing protocol. *Significantly different from "before spa bathing", $p<0.05$ (repeated measures ANOVA and Dunett's test).

baseline (before spa bathing). ANOVA with repeated measures was performed to examine time-related differences. Dunett's test was used for multiple comparisons. Values were considered to be significantly different when $p<0.05$.

\section{RESULTS}

For samples taken after spa bathing, there was a significant decrease in the levels of cortisol (Fig. 1a). Meanwhile, there was a significant increase in the levels of CgA after spa bathing (Fig. 1b). For samples taken during the control period, there was no significant change in the levels of cortisol or $\mathrm{CgA}$.

Then we categorized the subjects into two groups 
according to mental health status: high-stress (GHQ- $28 \geqq 8$ and/or Zung-SDS $\geqq 42$ ), and lowstress (GHQ-28 $\leqq 7$ and Zung-SDS $\leqq 41$ ) groups. When comparing results for samples taken from these two groups during the spa-bathing protocol, we found that the low-stress group showed significantly increased $\mathrm{CgA}$ levels after spa bathing (Fig. 2b). In the high-stress group, however, there was no such change. Moreover, the high-stress group had relatively greater reductions in salivary cortisol levels than the low-stress group (Fig. 2a).

Subjective perception of stress, evaluated using a visual analog scale, decreased significantly after spa bathing (Fig. 3).

\section{DISCUSSION}

The salivary cortisol levels showed a significant decrease after spa bathing (Fig. 1a). This finding suggests that spa bathing does relieve stress. The lower self-reported stress, significantly down after spa bathing (Fig. 3), also supports this finding. Moreover, the high-stress group had relatively greater reductions in salivary cortisol levels than the lowstress group (Fig. 2a).

$\mathrm{CgA}$ is known to be co-released with catecholamines during exocytosis $(15,16)$. Previous studies have reported significantly increased catecholamine levels, particularly noradrenaline, in association with sauna bathing $(3,5,6,8,9)$. This increase could be caused by increased sympathetic activity in response

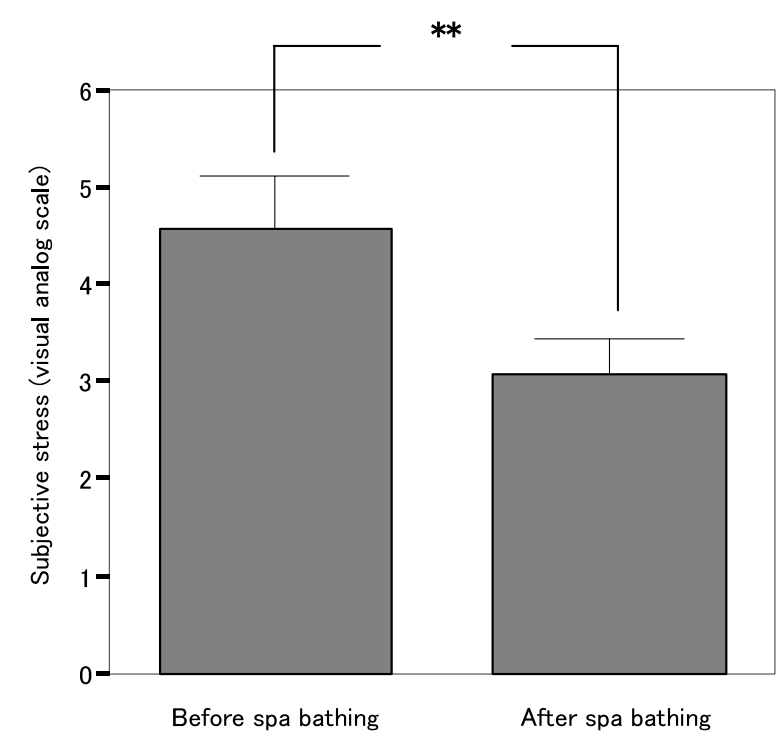

Fig. 3 Change in subjective stress (mean values $\pm S E$ ) after spa bathing $(n=12)$. ${ }^{* *}$ Wilcoxon matched-pairs signedranks test: $Z=-2.70, p<0.01$. to thermal stress. In the present study, the salivary $\mathrm{CgA}$ levels in the low-stress group showed the same tendency (Fig. 2b). In the high-stress group, by contrast, salivary CgA levels after spa bathing showed a tendency to decrease. These findings suggest the presence of a mechanism that attenuates excessive stress. Under normal conditions, spa bathing increases sympathetic activity because the temperature of the water constitutes moderate stress conditions. Under high-stress conditions, however, sympathetic activity reaches its limits with the addition of thermal stress. Consequently, a mechanism may intervene to restrain enhanced sympathetic activity under certain stress conditions. The more pronounced decrease in the salivary cortisol levels of the highstress group supports this hypothesis.

The present findings suggest that spa bathing can have a moderate effect on stress for mildly stressed persons, through increased sympathetic activity, or for more highly stressed persons, through some hypothetical endogenous mechanism. This suggests that spa bathing could play a useful role in medical therapy. The present study was conducted in a local spa. Because the waters of different spas vary in temperature and mineral content, to establish whether spas generally have the same effect on stress, we are planning further studies on various spas and populations.

\section{REFERENCES}

1. Fukuda K and Kobayashi S (1983) The Japanese Version of the SDS. Sankyobo, Kyoto.

2. Goldberg DP (1978) Manual of the General Health Questionnaire. NFER Publishing, Windsor.

3. Hussi E, Sonck T, Pösö H, Remes J, Eisalo A and Jänne J (1977) Plasma catecholamines in Finnish sauna. Ann Clin Res 9, 301-304.

4. Ježová D, Vigaš M, Tatár P, Jurčovičová J and Palát M (1985) Rise in plasma $\beta$-endorphin and ACTH in response to hyperthermia in sauna. Horm Metab Res 17, 693-694.

5. Ježová D, Kvetňanský R and Vigaš M (1994) Sex differences in endocrine response to hyperthermia in sauna. Acta Physiol Scand 150, 293-298.

6. Kauppinen K and Vuori I (1986) Man in the sauna. Ann Clin Res 18, 173-185.

7. Kirschbaum C and Hellhammer DH (1994) Salivary cortisol in psychoneuroendocrine research: recent developments and applications. Psychoneuroendocrino 19, 313-333.

8. Kukkonen-Harjula K and Kauppinen K (1988) How the sauna affects the endocrine system. Ann Clin Res 20, 262-266.

9. Laatikainen T, Salminen K, Kohvakka A and Pettersson J (1988) Response of plasma endorphins, prolactin and catecholamines in women to intense heat in a sauna. Eur J Appl Physiol 57, 98-102.

10. Lammintausta R, Syvälahti E and Pekkarinen A (1976) Change in hormones reflecting sympathetic activity in the Finnish sauna. Ann Clin Res 8, 266-271. 
11. Leppäluoto J, Ranta T, Laisi U, Partanen J, Virkkunen P and Lybeck H (1975) Strong heat exposure and adenohypophyseal hormone secretion in man. Horm Metab Res 7, 439-440.

12. Nagasawa S, Nishikawa Y, Jun L, Futai Y, Kanno T, Iguchi K, Mochizuki T, Hoshino M, Yanaihara C and Yanaihara N (1998) Simple enzyme immunoassay for the measurement of immunoreactive chromogranin A in human plasma, urine and saliva. Biomed Res 19, 407-410.

13. Nakane H, Asami O, Yamada Y, Harada T, Matsui N, Kanno $\mathrm{T}$ and Yanaihara N (1998) Salivary chromogranin A as an index of psychosomatic stress response. Biomed Res 19, 401406.

14. Shimada M, Takahashi K, Ohkawa T, Segawa M and Higurashi M (1995) Determination of salivary cortisol by ELISA and its application to the assessment of the circadian rhythm in children. Horm Res 44, 213-217.
15. Smith WJ and Kirshner N (1967) A specific soluble protein from the catecholamine storage vesicles of bovine adrenal medulla. Molec Pharmacol 3, 52-62.

16. Smith AD and Winkler H (1967) Purification and properties of an acidic protein from chromaffin granules of bovine adrenal medulla. Biochem $J$ 103, 483-492.

17. Toda M, Morimoto K, Nagasawa S and Kitamura K (2004) Effect of snack eating on sensitive salivary stress markers cortisol and chromogranin A. Environ Health Prev Med 9, 27-29.

18. Winkler H and Fischer-Colbrie R (1992) The chromogranins $\mathrm{A}$ and B: the first 25 years and future perspectives. Neuroscience 49, 497-528.

19. Zung WWK (1965) A self-rating depression scale. Arch Gen Psychiat 12, 63-70. 